\title{
Pattern of Analysis Students' Knowledge Construction Using Transcript-Based Lesson Analysis
}

\author{
Dea Santika Rahayu*, Setia Rahmawan \\ Department of Science Education \\ Universitas Pendidikan Indonesia \\ Bandung, Indonesia \\ *dea.santika65@gmail.com \\ Muslim Muslim \\ Department of Physics Education \\ Universitas Pendidikan Indonesia \\ Bandung, Indonesia \\ muslim@upi.edu
}

\author{
Sumar Hendayana \\ Department of Chemistry Education \\ Universitas Pendidikan Indonesia \\ Bandung, Indonesia \\ sumar.hendayana@gmail.com \\ Stevida Sendi \\ Department of Science Education \\ SMP BPI Bandung \\ Bandung, Indonesia \\ tetev.vita@gmail.com
}

\begin{abstract}
Constructivism approach is one of the studentcentered learning approaches, students actively build their own knowledge. Social constructivism views that students build new knowledge through their interactions and activities in the classroom, as well as the mediation role of cultural settings and discussion in which the knowledge construction occurs. The purpose of this research is to provide a pattern of analysis of students' knowledge construction using Transcript-based Lesson Analysis (TBLA) through Lesson Study for Learning Community. The method of this research is qualitative descriptive. This research involves students from Secondary School who are taught by a science teacher who is used to following lesson study activities. The learning activities were audio and video recorded. Then the recorded data were transcribed and analyzed. Dialogue analysis related to the students' knowledge construction was analyzed using TBLA that divided a learning process into several segments. The result shows that the profile of students' knowledge construction patterns in science learning consists of 3 segments, namely segment 1 which has a circulation pattern, segment 2 which has a circulation pattern and socialization of the last segment 3 which follows the circulation pattern, socialization and simulation. The role of teacher's questions and students' interaction help students to construct their knowledge.
\end{abstract}

Keywords: social constructivism, knowledge construction, TBLA, lesson study, science classroom

\section{INTRODUCTION}

In science learning, there are many concepts learned by students to explain the natural phenomena that occurred. The concept is built by students through various ways, one of which is the interaction between students with other students, teachers in the classroom. Knowledge construction can be interpreted as a process of how knowledge is formed when someone actively interacts with his environment that called social constructivism view [1,2]. In building an understanding, it always involves a new context in order to find out something that is not yet known, making explicit the tacit knowledge in order to be a context for discussion and understanding [3]. Knowledge construction is an effort of a "learner" to connect new knowledge with the basis of the knowledge it has rather than just remembering facts [4].

The process of constructing knowledge consists of three stages namely the pre-construction stage, the cognitive imbalance stage and the re-construction stage [5]. The new knowledge that has been construct includes ideal concepts, pseudo-science and wrong concepts. Therefore, the learning process that experienced by someone will guide how he construct his new knowledge and whether the construction results can be right or wrong. This is a challenge for teachers in developing ideal learning, so students are able to construct their knowledge appropriately.

In developing learning plans, teachers discuss with other teachers or with experts in activities called Lesson Study. Lesson study is a model of teacher professional development through the study of collaborative and sustainable learning based on the principles of collegiality and mutual learning to build learning communities [6]. Through Lesson Study, the teacher collaborates with other teachers or experts in preparing plans for learning, observe the learning and reflecting on the findings in the classroom to improve subsequent learning. Learning analysis is a way to see, hear, describe, discuss, and understand interactions between teachers and students during learning [7]. There are many learning analysis frameworks that have been developed by several experts, one of which is the analytical framework developed by Arani [8] that will be used by researchers in this study. In the preliminary study that the researchers had done in one of the junior high schools in Bandung, that are used to following lesson study activities, the researchers found that the teacher was accustomed to 
compiling and conducting learning that enlivens the activities of students in the classroom.

Based on the description, the main aim of this study is to analyze the construction patterns of students' knowledge in the science classroom through Lesson Study for Learning Community using TBLA. By doing this, we want to contribute to the current literature on students' knowledge construction by providing data. So, teacher can use this information as a source in developing more effective learning. The research problem is presented in the following questions:

- How is the profile of students' knowledge construction pattern that occurs in science classroom?

- What are the factors that influence the construction of knowledge in science classroom?

\section{METHODS}

The research method used in this study is a descriptive qualitative research method which emphasizes more on the nature of phenomena in detail [9]. This research was conducted to obtain a description of the pattern of students' knowledge construction of certain topics that occur in science classroom through Lesson Study activities. Participants in this study involved grade 2 students in one of the junior high schools in Bandung who had participated in Lesson Study activities for a long time, so that teachers who taught in the class were considered able to show natural and not tense performance during the observation.

This study consists of the three stages of learning, namely design, observation and reflection of learning. Analysis of the construction patterns of student knowledge is focused on the implementation of learning (observation), because the research aims to obtain descriptions of the pattern of Students' knowledge construction that occurs in science classroom.

In general, the flow of research conducted is divided into three stages, namely the stages of preparation, implementation and completion. The preparatory phase includes literature studies on junior high school science learning material to be carried out as well as conceptual pattern analysis from several textbooks and journals that aim to obtain essential concepts from junior high school science learning material. At the implementation stage of learning, researchers used the observation sheet instrument to observe the conceptual patterns that occur in science learning in the classroom. Observations during the learning process were assisted by other observers to strengthen the results of observations made. The entire activity at the stage of the research is recorded in audio and video, then the recorded data will be transcribed into verbal form for analysis. In the process of recording and collecting research artifacts (videos, photos, sound recordings, lesson plans, worksheets and observation sheets) researchers were assisted by other observers. At the completion stage, researchers conducted data analysis of learning transcripts to obtain the patterns of students' knowledge construction that occurred in science classroom.
The transcripts obtained were then analyzed the conceptual patterns that occurred in science learning using the Transcript Based on Lesson Analysis (TBLA) method. The process of TBLA analysis in this study is that researchers divide learning into several segments to be analyzed [8]. In this study, the segments were carried out based on the division of essential concepts constructed by students in each cycle according to the following Figure 1.

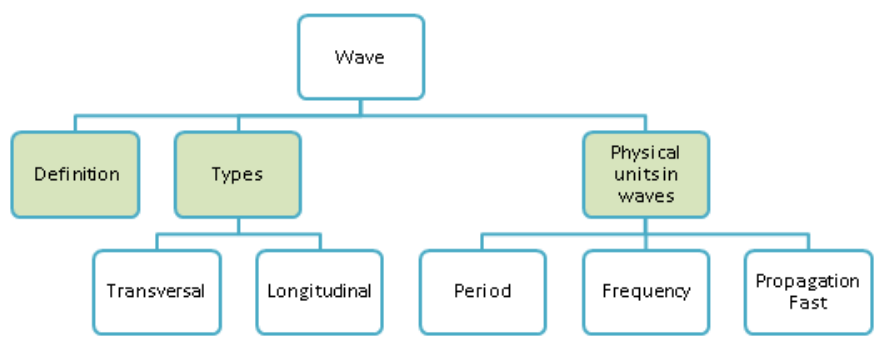

Fig. 1. Essentials concept.

Based on the Figure 1, there are 3 main concepts in this study namely Definition, Types and Physical in the wave. Each essential concept was analyzed including the pattern of analysis and the language function [1]. Analysis of knowledge construction can be seen based on dialogue. The boundaries of types of dialogue are potentially relevant to the construction of knowledge [10]. Furthermore, the following language functions during the discussion were adapted from Kumpulainen's study [11].

TABLE I. LANGUAGE FUNCTIONS

\begin{tabular}{|l|l|}
\hline \multicolumn{1}{|c|}{ Type of Response } & \\
\hline Informative & $\mathrm{I}$ \\
\hline Reasoning & $\mathrm{RE}$ \\
\hline Evaluative & $\mathrm{EV}$ \\
\hline Interrogative & $\mathrm{Q}$ \\
\hline Responsive & $\mathrm{A}$ \\
\hline Organizational & $\mathrm{OR}$ \\
\hline Agree & $\mathrm{Ja}$ \\
\hline Disagree & $\mathrm{Jd}$ \\
\hline Argumentation & $\mathrm{AR}$ \\
\hline Repetition & $\mathrm{RP}$ \\
\hline Experiential & $\mathrm{E}$ \\
\hline Affectional & $\mathrm{AF}$ \\
\hline
\end{tabular}

Students' dialogues are focused on students' utterance related to the construction of student knowledge and are grouped according to the type of response according to Table I [11].

\section{RESULTS AND DISCUSSION}

Based on the analysis of science learning in one of the junior high schools in Bandung, students construct their knowledge in different ways and the teacher becomes the student facilitator in constructing his knowledge. The dialogue between students and their environment will affect the construction of student knowledge. Therefore, the analysis conducted focuses on dialogue that builds students' knowledge 
in the classroom. The findings in this study were presented to answer the problem statement; (1) To describe the profile of students 'knowledge construction patterns in science learning and (2) To find out the factors that influence the construction of students' knowledge in science learning.

\section{A. Profile of Pattern Students' Knowledge Construction}

In analyzing the knowledge construction of students, researchers divide the wave concept into several essential concepts according to the Figure 1.

Each of essential concepts is constructed by students in learning through different patterns, so that learning is segmented based on these essential concepts and described how students build their own knowledge based on the dialogue contained in learning. The findings in the study consist of 3 segments, namely segment 1 include the definition of waves, segment 2 includes the type of wave and segment 3 includes the amount in waves.

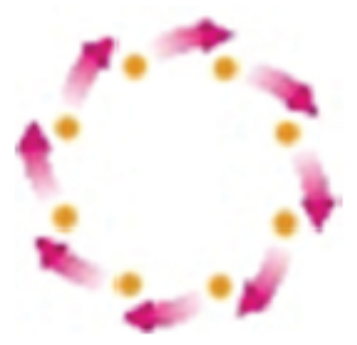

Fig. 2. Circulation pattern.

In segment 1, students construct their knowledge following a circulation pattern to build the concept of wave definition according to the Figure 2. Circulation patterns emphasize how people gain knowledge by interacting with multiple dimensions of this knowledge. Each dimension is like a mini-knowledge base through which students gradually make sense of the knowledge [1]. In this case the students build their knowledge through discussion activities guided by the teacher who directs the correct concept. Each student expresses his opinion regarding the definition of waves in different perspectives and integrates them into complete knowledge. Examples of conversations that show circulation patterns are in the following conversation:

- T30: Form a wave, so what is the wave?

- S5: Curved movements form a half circle

- T31: Okay, the movement that forms like a half circle. is it always half circle?

- S4: Movement that makes waves

- S9: Up and down movement when the rope is vibrated

Based on these conversations students are free to express their opinions as initial knowledge, while the teacher becomes the facilitator in directing each student's opinion to build his knowledge.
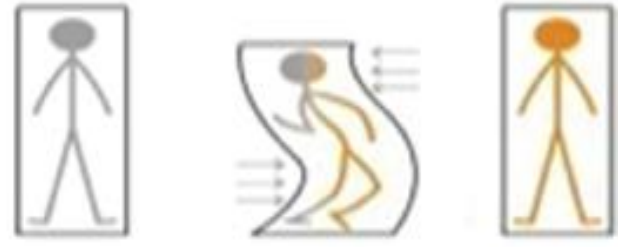

Fig. 3. Socialization pattern.

In segment 2, students construct their knowledge to follow circulation and socialization patterns to develop the concept of wave types. In this segment wave types are focused only on transverse and longitudinal waves. In the circulation pattern, students hold class discussions about the concept of transverse waves accompanied by observations of the vibrating rope. Every student has his own understanding expressed in the discussion. The pattern of socialization occurs when students construct the concept of defining 1 wave in a transverse wave. Socialization emphasizes how people are involved in the changed sociocultural context, molded by the mainstream directions through selective learning, the new context, and finally adapting to the new knowledge (see Figure 3). Students have an initial understanding of the definition of 1 vibration at the previous meeting which will be used to calculate the definition of 1 wave in the transverse wave, but there are some students who misinterpret the definition of 1 wave. Therefore, it is necessary for the help of teachers who can provide explanations for new concepts and students will combine this new knowledge with their initial knowledge to produce intact knowledge. Examples of conversations that show a pattern of socialization are in the conversation below ( $\mathrm{T}=$ teacher; $\mathrm{S}=$ Student):

- T34: Yes, because one vibration returns to its initial position, do you think that about one vibration is the same or not with waves?

- All S: Yes, ma'am

- S12: Difference

- T35: Okay, yeah, it's the discussion. Okay pay attention. if there is someone who answers the same or who answers differently about one wave. So the wave generated from? (Show the PowerPoint)

- S8: a to c

- T37: According to S8 a to c another?

- S7: a to e

- S19: a to d

Based on the conversation, there were differences of opinion between students regarding the definition of 1 wave. This shows that each student has the initial knowledge to define 1 wave, but there is a correct opinion and a wrong opinion. Therefore, to help students, the teacher displays learning media in the form of power points that display images of transverse waves, so students are able to observe the waves. 


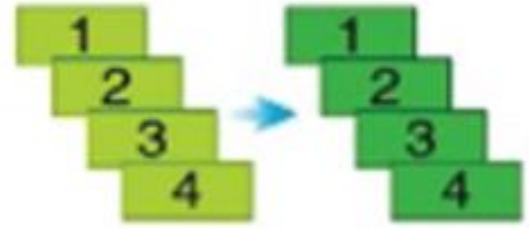

Fig. 4. Simulation pattern.

In segment 3, students construct their knowledge following the pattern of circulation, socialization and simulation to build the concept of physical quantities in waves (amplitude, period, frequency) according to Figure 1. Circulation patterns that occur in this segment are in the form of inter-group discussion activities guided by teachers where students express their opinions alternately, while the socialization pattern that occurs is when developing the wavelength concept. In the previous segment students have known the definition of 1 wave. Then the teacher provides new knowledge that is connected with units of length to find wavelengths. In order to help knowledge construction, teachers reuse power point media to provide a description of wavelengths, namely the distance of waves divided by the number of waves. Furthermore, the pattern of simulation occurs when building the concept of wave propagation to calculate the value. The simulation pattern can be imagining as the systematic by Figure 4. Simulation emphasizes how people suitably analogous knowledge gain through a process of observation, imitation, and adaptation [1]. In learning, the teacher provides systematic steps to calculate the wave velocity through discussion activities and write down the calculations on the board. Students observe each step taken by the teacher and record the calculation steps in the student worksheet. To evaluate students' understanding regarding the concept of wave velocity, the teacher provides practice questions related to calculating the wave velocity that must be done by students. Students discuss in their groups and fill in the worksheets provided. Examples of conversations that show a simulation pattern are found in the conversation below:

- T339: Already, now. in that case. pay attention ... how is the wave velocity? If it is known that the time it takes 4 seconds, then what should I look for here?

- S18: Lamda

- T340: How many waves?

- S8: Two

- T341: Two waves, what time?

- S8: 4 seconds

- T342: How many waves with time mean what can you find?

- S8: Period

- T343: Period, okay the formula?

- S7: $t$ divided by $n$

\section{B. Factors Affect the Knowledge Construction in Science Classroom}

Based on the analysis of learning that has been done, there are several factors that influence the construction of student knowledge in classroom learning. Researchers classify in general, there are 2 factors that influence the construction of knowledge, namely teachers and students in the group. The teacher becomes an important factor in guiding students to build knowledge. When students experience cognitive conflict between their initial knowledge and new knowledge acquired, the teacher helps students through elaboration questions. The role of teacher questions is to guide students in classroom learning. Teacher guides student to construct their knowledge using questions step by step, so students can understand the knowledge from the real context to the abstract concept [12].

In science classroom, the aid of the questions in stimulating students' thinking and making it explicit to the student as well as to the entire class. Also, teachers made active attempts to engage all the students in the discussions and move them towards conceptual understanding. Teacher's role is to help students in developing understanding of concepts and to build their personalities [13]. A Teacher, who has good communication can facilitate in the classroom and able to get students to explain things in an easily understandable manner. The explication of the data also reveals that students learn to think and evaluate in presence of an expert facilitator [14]. The role of teachers' question emerges to be of utmost significance in initiating discussion through the selection of appropriate questions, allowing students to be heard and on the hunt to the possibility of further discussion. It is noted that the questions asked should be oriented towards discussion and communication of different ideas that are directly associated with the in-depth knowledge of the subject. These questions should provide opportunities for students to reinvent ideas through exploration and refining of previous ideas.

Besides the second factor question is the interaction of students with their environment in learning. Students in constructing their knowledge interact with teachers and other students. The more students interact; the students will gain a lot of knowledge which will then be selected into new knowledge. The following Figure 5 presents an analysis of the types of students' dialogue have classified according to Kumpulainen [11].

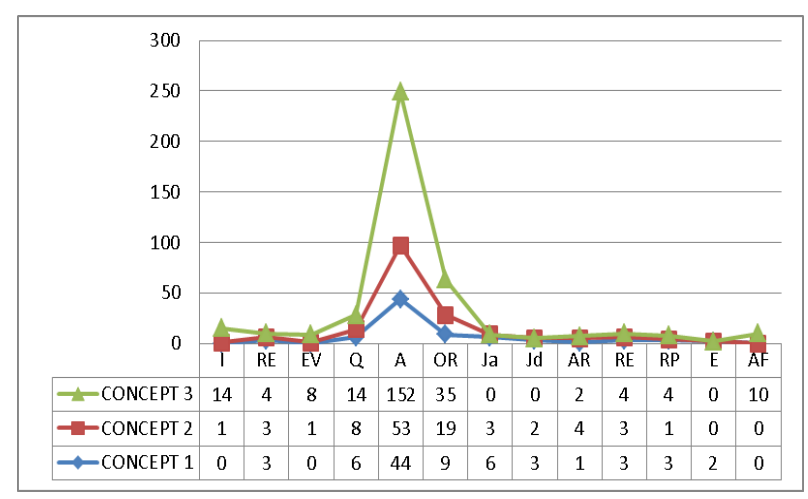

Fig. 5. Analysis of the types of students' utterance. 
[3] G. Stahl, Building collaborative knowing. In What we know about CSCL. Springer, Dordrecht, 2004, p. 53-85

The picture shows that the conversations of students from segment 1 to segment 3 have increased, especially the response of students in answering questions. This shows that students will express opinions when the teacher is able to guide in learning.

\section{CONCLUSION}

The main results of this study are categorized into two answers the questions problem show that (1) The profile of students' knowledge construction patterns in science learning consists of 3 segments, namely segment 1 which has a circulation pattern, segment 2 which has a circulation pattern and socialization of the last segment 3 which follows the circulation pattern, socialization and simulation. (2) The factors that influence the construction of students' knowledge in science learning. The role of teacher's question is to help students in developing understanding of concepts and to build their personalities. Their own roles might be in helping students develop scientific understanding through science learning process. In addition, student interaction with other students will help students gather a lot of information to build knowledge.

\section{ACKNOWLEDGMENT}

We are grateful to the teachers and students who participated in our project. We thank the principal of SMP BPI Bandung who allowed us done the research in the school, all teachers as observers who provided extensive research support and valuable discussion on the draft of this paper. Our sincere thanks to the reviewer of this paper for useful comments.

\section{REFERENCES}

[1] B. Chang, Pattern of Knowledge Construction. Adult Education Quarterly, 2018, pp 1-29.

[2] L. Vygotsky, Zone of proximal development. Mind in society: The development of higher psychological processes, 5291, 157, 1986.
[4] B. Ertl, M. Reiserer, and H. Mandl, "Fostering collaborative learning in videoconferencing: The influence of content schemes and collaboration scripts on collaboration outcomes and individual learning outcomes," Education, Communication \& Information, vol. 5, no. 2, pp. 147-166, 2005 .

[5] S. Rahman, R.M. Yasin, K. Jusoff, S.F.M. Yassin, N.M. Nordin and M.M. Yusof, "Knowledge construction process in online learning," Middle East Journal of Scientific Research, vol. 8,no. 2, pp. 488-492, 2011.

[6] S. Hendayana, S. Sukirman and M.A. Karim, "Studi dan Peran IMSTEP dalam Penguatan Program Pendidikan Guru MIPA di Indonesia," Educationist, vol. 1, no. 1, pp-28, 2007.

[7] L. Romagnano, B. Evans, and D. Gilmore, "Using video cases to engage prospective secondary mathematics teachers in lesson analysis," Cases in mathematics teacher education: Tools for developing knowledge needed for teaching (AMTE Monograph 4), pp. 103-115, 2008.

[8] M.R.S. Arani, Y. Shibata, K.E. Christine Lee, H. Kuno, M. Matoba, F> Lay Lean, and J. Yeo, "Reorienting the cultural script of teaching: cross cultural analysis of a science lesson," International Journal for Lesson and Learning Studies, vol. 3, no. 3, pp. 215-235, 2014.

[9] J.R. Fraenkel, N.E. Wallen and H.H. Hyun, How to design and evaluate research in education. New York: McGraw-Hill Humanities/Social Sciences/Languages, 2011.

[10] B. Schwarz, T. Dreyfus, N. Hadas, and R. Hershkowitz, Teacher Guidance of Knowledge Construction. International Group for the Psychology of Mathematics Education, 2004.

[11] K. Kumpulainen and M. Mutanen, "The situated dynamics of peer group interaction: An introduction to an analytic framework," Learning and instruction, vol. 9,no. 5, pp. 449-473, 1999.

[12] D.S. Rahayu, "Types and the role of teacher's questions in science classroom practice," Journal of Physics, pp 1-6, 2018.

[13] A. Benedict-Chambers, S.M. Kademian, E.A. Davis and A.S. Palincsar, "Guiding students towards sensemaking: teacher questions focused on integrating scientific practices with science content," International Journal of Science Education, vol. 39, no. 15, pp 1977 2001, 2017.

[14] M. Golkar, "Classroom Observation: Interaction Time and Question and Answer Patterns (Acceptance Sent), Indian journal of applied linguistics, vol. 29, no. 2, pp. 79-89, 2003. 